\title{
Value in Triangulation: A Comparison of Two Approaches for Combining Qualitative and Quantitative Methods
}

\author{
M. J. Gallivan \\ Stern School of Business \\ New York University \\ 44 W. $4^{\text {th }}$ Street, MEC 9-77 \\ New York, New York 10012 USA \\ Tel: (212) 998-0824 \\ Fax: (212) 995-4228 \\ E-mail:MGalliva@stern.nyu.edu
}

\begin{abstract}
This paper raises and pursues the question of why research utilizing mixed, quantitative and qualitative methods has been so strongly advocated, yet so little achieved. Following an overview of a range of solutions to the call for "ethodological pluralism," a conceptual framework for understanding the process and outcomes of mixed method research is advanced, and several research studies are used to illustrate the framework. The conceptual framework is based on two dimensions suggested by prior research. Specifically, the framework analyzes various outcomes that emerge from the research - such as different types of contradictions (Robey 1995) and also whether the two methods were employed sequentially or independently. The paper analyzes the relationship between these two dimensions of the framework, offering some possible reasons why mixed-methods studies in which the two methods are employed independently appear to lead to different outcomes.
\end{abstract}




\section{INTRODUCTION}

Research in the field of information systems (IS) has been frequently criticized for its strong allegiance to positivist assumptions and quantitative research methodology. In previous working conferences of the IFIP Working Group 8.2, various authors have criticized the bias toward positivist philosophy and empirical, hypothesis-testing methods. Research published in mainstream U.S. journals has been especially singled out for this criticism. One team of 8.2 researchers argued that

Information systems and information technology are so new that it is positively dangerous to allow them to be researched using only one methodology....We should currently be generating ideas, theories and hypotheses, rather than simply testing them, and that anything which restricts or constrains this process is inappropriate.

It is often argued that the degree to which the problem exists differs from geographical area to area...in Europe and perhaps in Canada more freedom exists to choose something other than a purely natural science form of enquiry, [and] alternatives are sometimes tolerated and live almost happily side-by-side....However, in the United States, this appears to be even less common, and a study of doctoral programmes confirms this. A worrying aspect of this being that the United States is...the most influential, and potentially the most successful IS society. The rest of the world needs the United States to widen its methods of enquiry in order for this success to be fully realised. [Fitzgerald et al. 1985, pp. 5-6]

Thus, for over a decade there has been a call for greater "methodological pluralism" in IS research, and participants in IFIP 8.2 have been some of its staunchest advocates. Given the emerging position that such pluralism is needed, the options for providing it abound. Several alternative research approaches have been proposed, and many have recently become more common in IS publications - even in U.S.-based mainstream journals. These include a greater frequency of research that is interpretive (Walsham 1995; Orlikowski 1993, 1996), research that combines positivist and interpretivist approaches (Lee 1991), and research that involves qualitative analysis of case studies (Eisenhardt 1989; Leonard-Barton 1990).

While each of these research approaches pose one solution to the problem that Nissen (1985) labeled a "methodological quagmire," this paper focuses on another alternative: research employing quantitative and qualitative research methods to develop or to test theory. This type of research has been widely prescribed, but rarely implemented. More than seventeen years ago, Jick claimed that "research designs that extensively integrate both fieldwork (e.g., participant observation) and survey research are rare" (Jick 1979, p. 604). We begin with the assumption that little has changed in terms of the frequency of mixed quantitative and qualitative research during the years since Jick's observation. This paper seeks answers to the following questions: In the IS field, how prevalent is mixed quantitative and qualitative meth- 
ods research - both in raw numbers and as a proportion of published papers? Why do IS researchers conduct such research? What are some attributes of mixed quantitative and qualitative research that may explain its unique contribution? These questions are explored in this paper, leading to a framework which classifies different types of mixed methods research. Mixed methods papers are not homogenous, but basically fall into two categories: applying quantitative analyses and qualitative analyses independently or sequentially. A contribution of this paper is to characterize these two categories of mixed-methods research and to discuss the outcomes associated with each.

\section{DEFINITION OF MIXED, QUANTITATIVE AND QUALITATIVE RESEARCH}

Merely invoking the phrase mixed methods research opens a pandora's box of questions and issues. First, the phrase mixed methods connotes different techniques to different researchers. For example, it may indicate research employing two or more different ways of measuring the same phenomenon, such as two survey scales for capturing user involvement in system implementation. Using two measures based on the same research method is excluded from the definition of mixed methods used here, since that is merely "within-method triangulation" (Denzin 1978; Jick 1979). Similarly, studies that employ two variations of qualitative research - such as longitudinal and retrospective case studies (Leonard-Barton 1990) - are also excluded.

The definition of mixed methods in this study refers to the mixing of quantitative and qualitative methods. This definition derives from Denzin and from Jick and their notion of triangulation between or across methods - in particular, qualitative and quantitative research. It is not the mere collection of data by two different methods that is relevant here, but also the analysis of such data. Jick defined mixed methods as "research designs that extensively integrate both fieldwork and survey research" (emphasis added). The significance of the word "extensively" implies that both qualitative and quantitative data must be collected and analyzed in the study. Based on the concepts of Denzin and of Jick, concepts, this refers to studies that are both conducted and published as mixed methods research. Mixed methods research is thus defined as empirical research ${ }^{1}$ that meets the following conditions:

- at least two different methods are used for collecting data

\footnotetext{
${ }^{1}$ There have been numerous conceptual review articles describing the strengths and weaknesses of various research methodologies (McGrath 1982; Benbasat 1984; Wynekoop and Conger 1991; Wynekoop and Russo 1993; Nissen 1985) and the variety of available qualitative methods (Lacity and Janson 1994). This paper does not include papers about methodology even those discussing mixed method research - unless an empirical study is presented in the paper.
} 
- at least one of the data collection methods is qualitative (e.g., interviews)

- at least one of the data collection methods is quantitative (e.g., surveys)

- both qualitative and quantitative data are presented

- both qualitative and quantitative data are analyzed

- the research addresses a theoretical question rather than providing description only

A published study must meet all six criteria in order to satisfy the definition of mixed quantitative and qualitative research. One class of research papers that is clearly excluded by this definition is studies where interviews were conducted simply as a precursor to developing a survey, and where the qualitative results are not presented. It has become commonplace to engage in qualitative interviews prior to conducting a survey; however, in many studies, the qualitative data are omitted from the results or mentioned only to provide anecdotes to support the survey results. This has been decried as "pseudo-triangulation" (Maxwell 1993) or using qualitative evidence as mere "window dressing" (Jick 1979).

Several studies were found that achieved four or five of the above criteria, but they were excluded from this paper for failing to meet each and every one of the criteria. For example, studies excluded were those that collected both types of data but did not present or analyze results of the quantitative data (Leonard-Barton 1990) or the qualitative data (Grant and Higgins 1991; Smith, Milberg and Burke 1996). Also excluded were studies that presented raw survey data without any quantitative analysis (Tyran et al. 1992) or studies that did not answer a theoretical question, such as descriptive Delphi studies (Watson 1990). Other definitions of mixed quantitative and qualitative research are certainly possible; however, the definition used here is faithful to Jick's definition as research that "extensively integrates both field work and survey research" to answer an empirical research question. ${ }^{2}$

Before presenting results from a structured review of the IS literature, it is important to underscore that this paper focuses on the type of data (qualitative and quantitative), rather than the type of theory or the epistemological assumptions used in analyzing the data. Although the terms qualitative and quantitative are often conflated with two other dimensions - epistemology (interpetivist and positivist) and logical structure of theories (process and variance) - these other dimensions are neither perfectly correlated with nor independent of the qualitative-quantitative distinction. The definition of mixed methods research used here assumes nothing about whether the

${ }^{2}$ One other category of articles that initially appeared to meet the definition of mixed methods research was those studies that collected all data through one method - qualitative interviews - and then coded and analyzed the data as quantitative results (Earl 1993; Reich and Benbasat 1996). Although such studies employ both qualitative collection and quantitative analysis of data, they are not mixed method studies, because only a single data collection method (interviews) and data analysis method (quantitative analysis) were used. No triangulation is possible on a single set of data. 
researcher seeks to combine positivist and interpretivist approaches or process and variance theories. These issues are distinct from the type of data that are analyzed and have been addressed by other researchers (Lee 1991; Markus and Robey 1988; Soh and Markus 1995; Mohr 1982). The definition of mixed methods research allows for methodological pluralism, permitting the data to be analyzed from either a positivist or an interpretivist perspective, and the theory to be constructed as either variance or process theory. Although some researchers believe that qualitative or "Qualitative" research (with an upper-case "Q") implies an interpretivist perspective (Kidder and Fine 1987; Maxwell 1996), no such assumption is made here. ${ }^{3}$

As stated above, we began with the assumption that mixed methods research has not increased in frequency since Jick's statement in 1979. Two pieces of evidence contributed to this assumption. The first was the observation by Orlikowski and Baroudi (1991) that only $3 \%$ of papers published in a set of U.S. journals were mixed methods studies. ${ }^{4}$ Second, the Proceedings of the Fourtheenth International Conference on Information Systems (DeGross, Bostrom and Robey 1993) were examined, since "valuing diversity through information systems" was the theme of that particular annual conference. No examples of empirical, mixed methods research were identified in the 1993 Proceedings, despite the diversity theme. Although this finding was disappointing, it confirmed the assumption regarding the scarcity of mixed methods and also prompted a more structured review of the IS literature. This structured review of four U.S. journals that publish IS research was conducted for the years 1988 to 1996. Since the prior literature review by Orlikowski and Baroudi covered the period from 1984 to mid-1988 in four leading U.S. journals, this review focused

\footnotetext{
${ }^{3}$ Qualitative research tends to be interpretivist and process-oriented, and quantitative research tends to be positivist and variance-oriented. Although research studies tend to cluster at one or the other end of these three dimensions, there are enough exceptions to recognize that the dimensions are somewhat independent of each other. In view of such independence, this paper does not seek to address the two related questions of whether researchers can combine positivist and interpretivist epistemologies or variance and process-oriented research. The definition of mixed methods research encompasses data that are analyzed under either a positivist or interpretivist paradigm, thus avoiding the "epistemological debate" (Sabherwal and Robey 1995). This definition includes research that combines mixed methods, whether the theory is a factor or process theory, or whether the researcher uses positivist or interpretivist philosophy. The debate as to whether different theories and epistemological assumptions are complementary, incompatible, or reconcilable is avoided here. These issues are subjects of debate among researchers (Lee 1991 1989; Markus and Robey 1988; Mohr 1982).
}

${ }^{4}$ In their review, Orlikowski and Baroudi classified only $3.2 \%$ of the articles as "mixed methods," based on four U.S. publications from the period 1984 through mid-1988. The journals they reviewed were MIS Quarterly, Management Science, Proceedings of the International Conference on Information Systems, and Communications of the ACM. Orlikowski and Baroudi did not specifically define mixed methods, although their category of mixed methods publications would appear to overlap the definition used here. 
on the subsequent period (1988-1996), based on similar U.S.-based journals, but a slightly different subset. All papers published in three IS journals (MIS Quarterly, Information Systems Research, and Journal of Management Information Systems) were reviewed, as well as IS papers published in Organization Science. ${ }^{5}$

A total of 583 papers from these four journals were reviewed, with eleven papers meeting the definition of mixed quantitative and qualitative research. The frequency of such papers is only $1.9 \%$ across these four journals. Table 1 shows that MIS Quarterly published a higher ratio of such papers, while Information Systems Research and Journal of Management Information Systems published fewer such studies. In addition to the structured review, other examples of mixed methods research were sought by following references from two review articles of IS methodology - one from IFIP 8.2 (Wynekoop and Conger 1991) and another from ICIS (Wynekoop and Russo 1993). This helped to identify other mixed methods studies, even those published in other journals. ${ }^{6} \mathrm{~A}$ total of five additional papers were located by following citations from these papers, resulting in a total of sixteen mixed methods studies that were reviewed and analyzed in order to develop a conceptual framework, described below.

\section{CONCEPTUAL FRAMEWORK}

All sixteen mixed methods papers were analyzed and found to differ along several dimensions. A preliminary classification of these papers revealed that they differed in terms of

- whether the initial results of the qualitative and quantitative analyses were complementary, contradictory, or unrelated to each other;

- whether the paper's final theoretical contribution required the separate insights of both methods, or whether the theoretical insights could have been reached from one method alone.

Analysis of these papers revealed that half (eight papers) identified a contradiction in their results. Of the remaining papers, two did not identify any contradiction, but they

${ }^{5}$ MIS Quarterly was the only journal included in both this study and in the Orlikowski and Baroudi review. Management Science was not reviewed here, since it now publishes fewer papers related to IS research, compared to the past. Two new journals, Information Systems Research and Organization Science, were reviewed here but not in the study by Orlikowski and Baroudi because these journals started publication in 1990. Journal of Management Information Systems was also included in this literature review.

${ }^{6}$ The term other journals refers to journals other than those in which the structured literature review was conducted. For example, Barley's two papers $(1986,1990)$ are included here because they are widely cited as mixed methods studies, although Administrative Science Quarterly was not one of the journals included in the structured literature review. 
Table 1 Mixed Method Studies Located through Structured Review of IS Publications.

\begin{tabular}{|c|c|c|c|c|c|}
\hline Journal Title & $\begin{array}{c}\text { Review Start } \\
\text { Date }\end{array}$ & $\begin{array}{c}\text { Review } \\
\text { End } \\
\text { Date }\end{array}$ & $\begin{array}{l}\text { Number } \\
\text { of Mixed } \\
\text { Method } \\
\text { Papers }\end{array}$ & $\begin{array}{c}\text { Total } \\
\text { Papers } \\
\text { Published }\end{array}$ & $\begin{array}{l}\text { Percent } \\
\text { Mixed } \\
\text { Method } \\
\text { Papers } \\
\end{array}$ \\
\hline $\begin{array}{l}\text { Information } \\
\text { Systems Research }\end{array}$ & 1990 & 1996 & 2 & 124 & $1.6 \%$ \\
\hline $\begin{array}{l}\text { Journal of Man- } \\
\text { agement Informa- } \\
\text { tion Systems }\end{array}$ & 1988 & 1996 & 1 & 253 & $0.4 \%$ \\
\hline MIS Quarterly & 1988 & 1996 & 6 & 206 & $2.9 \%$ \\
\hline $\begin{array}{l}\text { Organization Sci- } \\
\text { ence }\end{array}$ & 1990 & 1996 & 2 & - $^{*}$ & - $^{*}$ \\
\hline Total Papers & 1988 & 1996 & 11 & 583 & $1.9 \%$ \\
\hline
\end{tabular}

Table 1a Mixed Method Studies Found in Other Publications.

\begin{tabular}{|l|c|}
\hline \multicolumn{1}{|c|}{ Journal Title } & $\begin{array}{c}\text { Number of Mixed } \\
\text { Method Papers }\end{array}$ \\
\hline Administrative Science Quarterly & 2 \\
\hline Communications of the ACM & 1 \\
\hline ICIS Proceedings & 1 \\
\hline Sloan Management Review & 1 \\
\hline Total Papers & 5 \\
\hline
\end{tabular}

*Only IS publications in Organization Science that employed mixed methods were reviewed. It is therefore misleading to calculate a percentage of mixed method papers as a ratio of total papers.

emphasized the importance of the two sets of findings (the quantitative and the qualitative) in providing a synergistic analysis of their data. The latter papers specifically emphasized that the resulting theory required integration of both the qualitative and quantitative findings. Finally, there were six papers without either of these 
attributes (they found no contradictions nor did they emphasize a synergy between the two sets of data).

Since Robey (1995) recently provided a framework for understanding contradictions in IS research, his terminology was used to as a starting point, although it was expanded. Robey's categories are contradictions within a single research study, contradictions among research studies, and studies with no contradictions. In the spirit of Robey's terminology, but acknowledging that the categories required here were necessarily more complex (due to the need to also recognize contradictions between the two sets of data within the same study), the following five categories were identified:

1. A study with contradictions that appear within it, due to the use of mixed methods.

2. A study with contradictions that appear within it, but where the contradiction was identified based on a single method alone (rather than due to the mixed methods).

3. A study without an inherent contradiction, but where some results are inconsistent with prior studies.

4. A study without any contradiction, and where a synergy exists between the results of the mixed methods.

5. A study without any contradiction, and where results are parallel but not synergistic between the mixed methods.

Papers were analyzed and classified according to these five categories, with the results shown in Table 2. Most papers were classified in rows 2 and 5 (five and six papers, respectively). Only five papers were classified in the other three rows of the table. Summaries of selected papers are described below, in order to illustrate the classification, and also to identify the theoretical contributions of mixed methods research.

\section{LITERATURE REVIEW OF SELECTED PAPERS}

Contradictions that appear within a study due to the use of mixed methods. In their study of the effect of computerized laboratory systems in hospitals, Kaplan and Duchon (1988) separately analyzed the results of interviews and surveys, which yielded two key contradictions. First, whereas quantitative analyses based on job characteristics theory (Hackman and Oldham 1980) revealed high levels of satisfaction and acceptance of the new system, the qualitative analyses revealed strong user dissatisfaction. Second, the qualitative analyses revealed patterns of intergroup dif- 


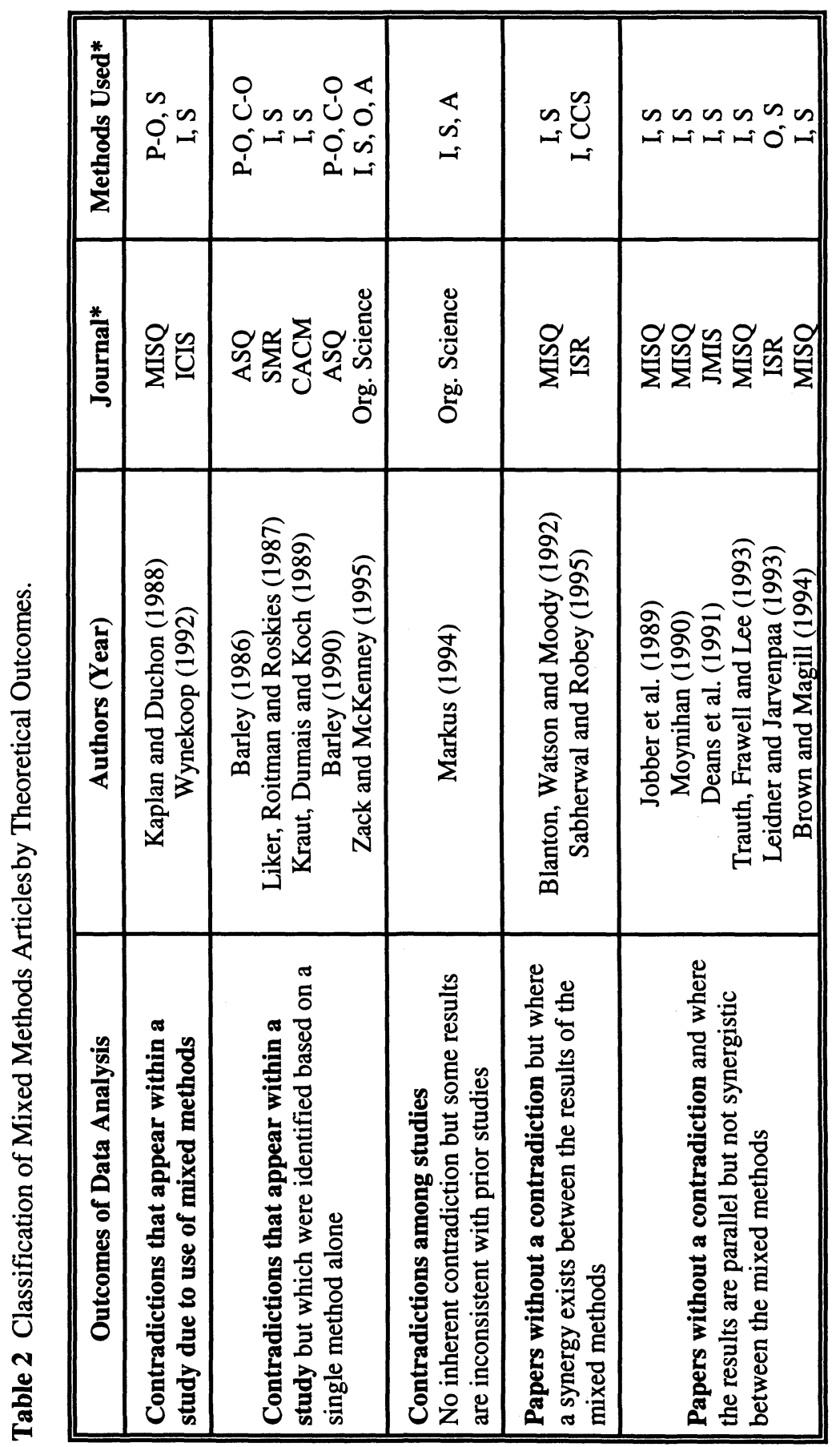

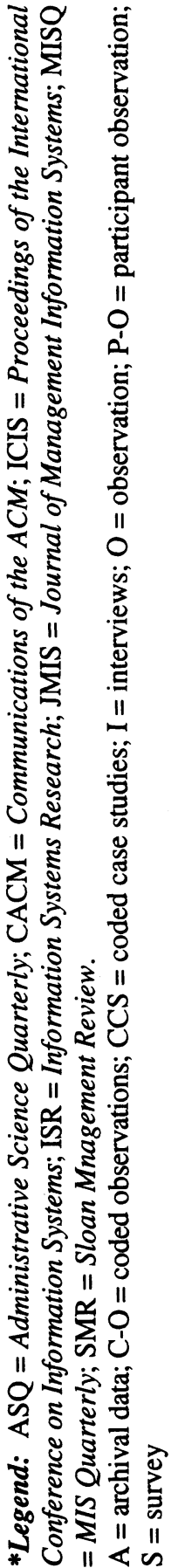


ferences in system acceptance (at the departmental level), however, such patterns were obscured in the survey data. ${ }^{7}$ After recognizing these contradictions, Kaplan and Duchon searched for an integrative explanation, ultimately identifying the new, group-level construct of work orientation as explaining users' acceptance of the system. Two work orientations were defined, with work groups labeled as either process-oriented or results-oriented. The process-oriented work groups perceived the system as interfering with their real work (conducting lab tests), whereas the resultsoriented groups perceived the system as streamlining their work (communicating lab results to other departments). This group-level construct - work orientation - successfully predicted individual workers' attitudes toward the system. Thus, the qualitative and quantitative methods independently generated contradictions that could only be resolved by developing new theory and validating it with existing survey data, through a novel procedure for computing sums and differences between existing items. The authors were highly motivated to resolve the contradiction between the divergent findings without negating either set of findings. Iterating between the two sets of results, the work orientation construct was operationalized and found to explain significantly the differences in individuals' reactions to the system.

A second study that reflected contradictions between mixed methods in the same study was Wynekoop's (1992) study of the implementation of CASE tools in seven firms. She employed both interviews and surveys to identify the factors and processes associated with successful adoption, leading to several contradictions: 1) the firms that were shown to have the strongest managerial support for CASE tools (in the field studies) had the lowest levels of user acceptance and actual usage (in the survey); 2) the firm in which the level of management support was lowest showed the highest levels of user acceptance and usage (in the survey); 3 ) the amount of positive communication about the benefits of CASE tools was inversely related to user acceptance across all firms studied. These were puzzling findings, since they were internally inconsistent and also contradicted prior evidence showing the importance of managerial support (Jarvenpaa and Ives 1991) and high levels of communication about the benefits of an innovation to potential adopters (Rogers 1983; Ives and Olson 1984).

Due to these contradictions among her results, Wynekoop reconciled them by identifying new constructs in the qualitative data, and then used them to explain anomalies in the survey data. The qualitative data suggested the importance of bottom-up and well as top-down management support for the innovation. The data also suggested the importance of accurate and complete communication about the benefits of CASE tools if they were to be successfully implemented and accepted by users. The importance of accurate and complete communication explained certain contradictions, because the survey data alone had only analyzed the amount of

${ }^{7}$ Differences between departments, in terms of user acceptance of the technology, were obscured in the survey data because the quantitative analysis captured only individual means and variances but did not aggregate the data by department to identify group-level differences. 
positive communication about CASE tools in each firm, but not its accuracy. Where such information was biased, the users rejected the technology after initial use. Similarly, the paradox of strong management support leading to user rejection was an artifact due to the fact that, in one firm where an overzealous IS manager championed the technology, he did so autocratically, so that grass roots support among users was stifled. In summary, the contradictions led to a re-examination of the qualitative data to identify new constructs (accurate and complete communication and bottom-up support), and then using them to reinterpret the survey data to resolve the contradictions.

Contradictions that appear within a study, but where the contradiction was identified based on a single method alone (rather than due to the mixed methods). Barley $(1990,1986)$ identified the inconsistent results of medical CT (computerized tomography) scanning technology in two hospitals. Using a mixed methods data collection strategy as well as a mixed-level analysis (focusing on both micro- and macro-level changes $\left.{ }^{8}\right)$, Barley showed that the opposite macro-level outcomes in the two hospitals could best be explained by differences in micro-level phenomena. In one paper, Barley (1990) showed that when the same technology was adopted within two different organizational contexts, it exerted different effects on organizational structure and patterns of interaction. One hospital became much more decentralized while the other hospital showed no changes in level of centralization (Barley 1986). In a related study, Barley (1990) showed that the same technology exerted different effects on communication patterns within the same hospital, depending on the age of physicians and the number of years they had been in practice. In the latter study, Barley employed quantitative sociometric data ${ }^{9}$ to show that different "relational role patterns" developed between the radiologists and the technicians using the new technology, but these patterns were influenced by the recency of physicians' specialty training and their use of the CT scanners.

${ }^{8}$ Barley (1990) used sociometric data to conduct a network analysis (communication frequency analysis), focused on both the frequency and duration of interactions among the radiologists and other paraprofessionals, including technicians. Quantitative network analyses verified that the CT scanner altered role relationships such that younger doctors, who used the CT scanner, had much stronger relationships with the radiology technicians, compared to the older physicians, who rarely used it. The analysis also showed that the radiology technicians who used the CT scanner became "structurally equivalent" to the radiologists in their communication patterns, whereas the technicians who did not use the CT scanner retained a traditional communication pattern, similar to other ancillary health workers.

${ }^{9}$ Markus and Robey (1988) describe the advantages of using mixed-level (or multi-level) research, which is facilitated by, but does not required mixed methods. Mixed-level research collects data at multiple levels of analysis (e.g., individual, group, organizational, or industry). Additional comments about mixed-level data are deferred until the paper's conclusion. 
No inherent contradiction but some results are inconsistent with prior studies. Markus (1994) collected data about managers' actual usage of e-mail and their reasons for using e-mail instead of other media. Markus used interviews, surveys, and analysis of sample messages. While her results did not show an inherent contradiction, the overall results were inconsistent with prior theory - namely media richness theory (Daft, Lengel and Trevino 1987). The three categories of data were internally consistent, showing that managers were not primarily influenced by media richness considerations, but rather by social influences which shaped their e-mail usage (Fulk, Schmitz, and Steinfield 1990). This contradicted the conventional wisdom that managers' choice of appropriate media (based on its richness ${ }^{10}$ ) influences their performance. Markus showed that media richness theory is a poor predictor of either managers' choices or how these choices correlate with their job performance.

Papers without any contradiction, but where a synergy exists between the results of the mixed methods. Sabherwal and Robey (1995) independently tested two theories, based on field studies of fifty system implementation projects. Although both the variance and process theories they developed were grounded in the same set of case studies, Sabherwal and Robey concurrently developed a quantitatively-oriented variance theory, which emphasized the amount of involvement by various stakeholders during implementation, as well as a qualitative process theory, which emphasized the sequences of events that occurred during system implementation. ${ }^{11}$ The qualitative data were then analyzed using optimal matching, a quantitative analytic technique. Rather than generating contradictory results, the qualitative and quantitative analyses were consistent with each other, but the independent analyses from the two theories were jointly combined to create a more powerful, synergistic theory than that possible with either method alone: "To demonstrate the benefits of joint applications of both [research] strategies, we also provided interpretations that could only have been drawn from using both together" (Sabherwal and Robey 1995, p. 321).

Papers without any contradiction, and where results are parallel but not synergistic between the mixed methods. Most papers in this category conducted field inter-

${ }^{10}$ Markus (1994, p. 505) paraphrased the definition by Daft and Lengel (1986) of media richness as "the ability of information and media to change human understanding, overcome differing conceptual frames of reference, or clarify ambiguous issues in a timely manner."

\footnotetext{
${ }^{11}$ Note that the distinction between the terms process and variance theory is not analogous to the distinction between qualitative and quantitative methods - a point that Sabherwal and Robey emphasize in their paper. In this particular study, however, the variance theory utilized quantitatively-coded data, and the process theory utilized qualitative data (based on event listings). The qualitative data were used to generate a process theory, and this theory was tested through optimal matching - a computerized quantitative analysis method based on dynamic programming. Although their analysis of the process theory has both qualitative and quantitative aspects, the study is included because it met the definition of mixed methods used here: both qualitative and quantitative data were presented and analyzed.
} 
views or observations as a precursor to administering a survey. For example, Brown and Magill (1994) developed case studies of six firms, examining the drivers of a firm's decision to centralize or decentralize its IS function. The authors also collected survey data from the same companies to capture the beliefs of additional respondents regarding the relationship between these drivers and structural decisions. Their findings included analyses of both types of data - which were consistent with each other - but did not involve a synergy. Their paper is labeled as having parallel results because the data from both methods were consistent with each other.

As these papers were analyzed to understand whether the authors identified a contradiction and also how they attempted to integrate the two sets of findings, a second important distinction was identified: whether the authors collected and analyzed the two sets of data independently of each other or sequentially. In conducting the study, mixed quantitative and qualitative data may have been collected and analyzed independently, with a separate researcher (or separate teams of researchers) collecting and analyzing each set of data. Alternatively, the process of collecting and analyzing the two sets of data may have been sequential, that is, where use of one method preceded the other, and hence the insights from one set of findings (e.g., qualitative data) were available for the researcher to elaborate upon or refute with the second method (e.g., quantitative analysis). ${ }^{12}$ This distinction between independent and sequential data collection and analysis was used as a second criterion with which to classify the same set of papers. The dimension is labeled the process of analyzing mixed methods data. Using this new criterion as one dimension and the rows of Table 2 as a second dimension, these papers were classified into a two-dimensional matrix (see Table 3). Most papers followed a sequential process for collecting and analyzing the data (twelve papers), but four studies analyzed the data independently. Each of these approaches to combining qualitative and quantitative data is discussed below.

\section{RESEARCH EMPLOYING MIXED METHODS INDEPENDENTLY}

In the studies that used mixed methods independently, there was emphasis on the importance of the two sets of data in generating a synergy, whether or not a contradiction was identified. Not only were the findings that emerged from the independent quantitative and qualitative analyses interesting when compared with each other, but the authors stated that the integration between both sets of results was critical in producing the study's insights. The papers that used both methods independently

\footnotetext{
${ }^{12}$ Other researchers have used terms such as joint, concurrent, and separate to describe research in which the qualitative and quantitative data were collected and analyzed independently (Sabherwal and Robey 1995; Maxwell 1993). Studies where the two sets of data were iteratively analyzed are also classified as sequential, for reasons of simplicity.
} 


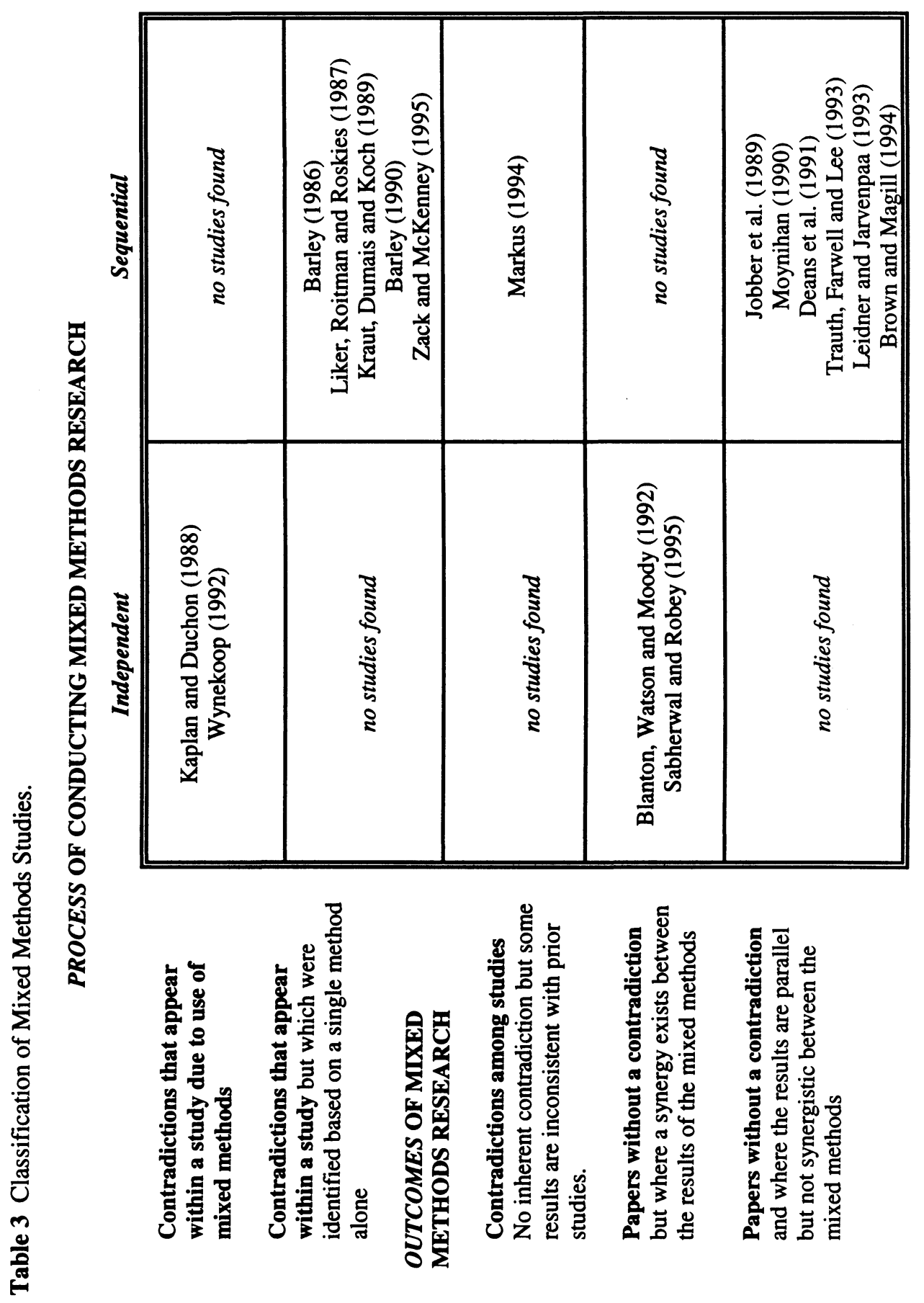


generated novel constructs or theories which required the integration of the qualitative and quantitative findings, either to resolve an inherent contradiction between the results from the two analyses (Kaplan and Duchon 1988; Wynekoop 1992) or to provide a synergistic theory which integrated the separate results (Blanton, Watson and Moody 1992; Sabherwal and Robey 1995). ${ }^{13}$

What is it about employing independent data analyses that leads to theoretical conclusions which draw upon both sets of data synergistically? Is there something about the process of independently collecting and analyzing two sets of data before combining them which actually increases the likelihood of significant theoretical contributions? These questions are explored by examining authors' statements about the importance of the independent analyses in providing their study's insights. These researchers suggest that, had they known about the one set of findings before undertaking the other analysis, their insights might not have been so rich - or so trustworthy.

First, Kaplan and Duchon (1988, p. 582) argued

Our tenacity in holding to our initial independent analyses of the different data...and the increased respect each of us developed for the other's approach, in fact, were positive aspects of our research....A strong determination to accommodate each approach and to reconcile apparently conflicting data resulted in an interpretation that synthesized the evidence. Consider Wynekoop's (1992, p. 187) statement that "Case studies were written from information gathered through semi-structured interviews...before the quantitative analysis was undertaken. Quantitative and qualitative data were analyzed independently and synthesized only after separate findings and conclusions had been reached" (emphasis added).

Sabherwal and Robey (1995) stated that they conducted their qualitative and quantitative analyses independently or "jointly." They specifically designed the research process to

implement the two strategies independently, making sure to avoid any overlaps between them....This method [joint application] is perhaps the most powerful way of combining... [different research] strategies because it preserves the distinctive strengths of both strategies by using them independently before combining their insights. Reconciliation of the different strategies using this method does not blur the important distinctions between them and offers potential synergy in interpreting results. [Sabherwal and Robey 1995, pp. 308, 323]

${ }^{13}$ Even some of the titles of these papers emphasize the integration between both methods: "Combining Qualitative and Quantitative Methods in IS Research: A Case Study" (Kaplan and Duchon 1988) and "Strategies for Implementation Research: Combining Research Methods" (Wynekoop 1992). 
Taken as a whole, the studies where researchers independently analyzed qualitative and quantitative data generated novel theoretical constructs: work orientation (Kaplan and Duchon 1988), accurate and complete communication (Wynekoop 1992), and the importance of both the level of participation and the timing of various stakeholders' actions during system implementation (Sabherwal and Robey 1995). Each of these novel constructs was developed to integrate the two sets of findings, whether to explain an inherent contradiction between the two sets of findings or to develop a synergy between the data. In fact, these novel constructs, which emerged from the research, were later elaborated in subsequent research, such as the importance of CASE tool adopters' work orientation to their acceptance of the technology (Orlikowski 1989, 1993), and the problems associated with not receiving accurate and complete communication about a technology (Griffith and Northcraft 1996).

\section{STUDIES EMPLOYING MIXED METHODS SEQUENTIALLY}

Turning now to the sequential process of conducting mixed methods research, twelve studies were identified in which the researchers collected and analyzed the qualitative and quantitative data sequentially. In most cases, these papers employed a traditional sequence of conducting interviews or observations prior to developing and administering a survey (although there were some exceptions where the survey data were collected first). Each paper's abstract, introduction, discussion and conclusion section was examined for any articulation of the relationship between the study's mixed methodology and its theoretical findings. Although all studies in the sequential category employed both qualitative and quantitative data collection and analysis, the importance of triangulating between the two sets of data was not emphasized in these papers. Indeed, it was possible that each paper's theoretical insights could have been reached on the basis of either the qualitative data or the quantitative data alone.

\section{DISCUSSION}

The prior examples showed that studies employing mixed methods sequentially neither generated inherent contradictions between the results from the two methods of the study nor strongly emphasized the need to integrate the findings resulting from the two methods. Why has less attention been focused on the opportunity or the need to integrate findings for those papers that employed mixed methods sequentially, compared to those studies employing them independently? Are the findings of the independent mixed methods studies truly more significant than the sequential studies, or have the authors chosen to emphasize the importance of independent analysis in generating their conclusions? 
The evidence above suggests a possible connection between the process and the outcomes of mixed methods research: independent mixed methods studies appear to be associated with an integration of the qualitative and quantitative findings, perhaps by not constraining one analysis (e.g., quantitative) by the findings that emerged from the other analysis (e.g., qualitative). In examining the factors that influence whether "stories converge," Kidder and Fine (1987, p. 55) argued that "the independent conduct of qualitative and quantitative evaluations is a greater challenge for triangulation, but it also holds promise for greater discovery."

The above examples and statements from researchers demonstrated their belief that independent mixed methods research can lead to greater synergies between the two sets of data, and possibly to more significant contributions, compared to sequential mixed methods research. The underlying mechanism between the two approaches for combining qualitative and quantitative data and their outcomes, however, is still unclear: why does independent analysis have this "promise for greater discovery"? Given the asymmetric patterns of studies in Table 3, it is obvious that some relationship exists between the two dimensions of the framework, but what is the nature of this relationship?

This relationship between the process and the outcomes of mixed methods research may be partially explained by Davis' (1971) argument that research which is considered interesting by readers is that which develops and then resolves a contradiction. The use of mixed methods independently may be more likely to generate inherent contradictions between the two sets of results within a single study, whereas sequential mixed methods studies may generate other types of unexpected findings, but not contradictions between two methods used in the same study. This is because when research collects and analyzes data using two methods independently, the findings are more likely to diverge or to contradict each other - at least initially. In contrast, when researchers collect and analyze two types of data sequentially, they have the opportunity to modify their procedures or to focus their analyses to ensure that their results more consistent, thus decreasing the likelihood of finding inherent contradictions. Inherent contradictions between two methods in the same study are one type of contradiction which, if resolved, lead to more interesting and significant findings (Davis 1971; Poole and Van de Ven 1989; Robey 1995). Davis' argument about the antecedents of interesting research is, at best, a partial explanation for why independent mixed methods research is more likely to lead to significant findings. There are, of course, other types of contradictions that may occur, as shown in Table 3 (rows 2 and 3).

\section{DO INTERESTING FINDINGS LEAD TO CLAIMS OF METHOD INDEPENDENCE?}

So far, it has been hypothesized that research which employs mixed methods independently is more likely to generate results that require integration across the two sets of data, compared to sequential mixed methods research. In examining this claim, 
however, note that the implicit direction of causality runs from the process of collecting and analyzing the data (independent or sequential mixed methods) to the study's outcomes, in terms of synergy across the two types of data. A rethinking of this association between the two dimensions of the framework (Table 3) raises the possibility that the true "causal link" between them runs in the opposite direction. Instead of the research process (independent or sequential) leading to more significant findings, it may be that the nature of the findings influences how researchers choose to frame the research process - either independent or sequential analysis of the data. ${ }^{14}$

\footnotetext{
${ }^{14}$ Due to the speculative nature of the following material, the program co-chair, Allen Lee, recommended that it be removed from the main body of the paper. Although some examples of independent mixed method research have been presented, the issues raised in here go beyond the available data, posing questions that may only be answered with further research.

One possibility is that researchers emphasize their independent use of mixed methods as a type of impression management to persuade the reader that their conclusions are more reliable because they are based on independent corroboration. For example, it may be that where an integration or synergy between the qualitative and quantitative findings is required to explain the study's results, researchers attempt to persuade readers of the independence of the two sets of findings in order to refute the notion that the insights from one analysis (i.e., quantitative) may have biased the other (i.e., qualitative). Conversely, where no such integration between the two sets of findings is necessary to understand the study's theoretical contributions, authors may portray their data analysis as being sequential, or not bother to mention the timing of the analyses at all. In the latter case, authors may even downplay one set of results, by treating one method as merely "subordinate or supplementary" to the other (Maxwell 1993).

Is it the case that some researchers engage in "impression management" by stressing the independent analyses of their data to persuade readers of the lack of bias in their findings? The quotes from the authors who independently employed mixed methods show that they do strongly emphasize the independent nature of their qualitative and quantitative analyses as a critical element in generating the paper's conclusions. Claiming that these analyses were conducted independently appears to add rhetorical force to the conclusions, even when the two types of data analysis (quantitative and qualitative) may have overlapped and provided insights for each other.

It may be that researchers believe that when one set of data (e.g., survey data) is analyzed after knowing the results from the other analysis (e.g., qualitative) their findings may be somehow tainted or less reliable. There also appears to be an implicit concern that the admission of sequential analysis may undermine readers' confidence in the findings, since researchers themselves believe that, when analyzing two sets of data, the results from one type of analysis may influence the other. Kidder and Fine $(1987$, p. 66) state that "We suspect that any researcher is more motivated to find agreement across conclusions within his or her study than are two or more researchers working independently."

This paper has focused on combining qualitative and quantitative research methods, without making any assumptions about the researchers' epistemological stance (positivist or interpretivist); however, the assumption that "independent" validation of results is necessary and valuable is itself a positivist tenet. The very concept of independent analysis and verification is a mainstay of positivist research, designed to ensure the reliability and convergent validity of findings. In contrast, interpretive researchers use a variety of other techniques to persuade readers of attributes such as "plausibility, criticality, and authenticity" (Golden-Biddle and Locke 1993), but not the accuracy or reliability of their findings. Despite
} 
This raises the possibility that the nature of the findings and conclusions in the paper may lead researchers to emphasize the independent nature of their research process. For example, studies that require an integration or synergy between the results of mixed methods may be more often portrayed as using mixed methods independently, rather than sequentially.

This provides a possible explanation for why there were no studies that correspond to the lower left cell in Table 3 (parallel findings based upon independent analyses). This cell implies a weaker set of findings, since it represents consistency - but no synergy - between the two sets of results. The absence of papers in this cell may be explained by the authors' decision 1) to reframe the results to highlight the synergy or contradictions between the two sets of data (moving up to another row on the left side of the framework), 2) to describe the research process as sequential, or 3) to publish the results as a single-methodology study, thus slighting one set of methods and results. Several examples of the latter case were found - where the authors used both methods to collect their data, but then omitted any analysis of either the quantitative data (Leonard-Barton 1990; Tyran et al. 1992) or qualitative data (Smith, Milberg and Burke 1996). This is consistent with Jick's argument that researchers often publish their results in such a way that one research method and its results are omitted (Jick 1979; Konsynski 1993).

It is probable that the triangulation approach is embedded in many doctoral theses that, when packaged into articles, tend to highlight only the quantitative methods....Moreover, journals tend to specialize by methodology, thus encouraging purity of method. [Jick 1979, p. 604-605]

Such studies, when published, would thus not appear to have employed mixed methods at all and would not be included in this paper's literature review or framework (Table 3).

\section{CONCLUSION}

This paper has shown that studies that employ mixed quantitative and qualitative methods are not homogenous, but differ on two dimensions: the process of combining the two methods and the study's outcomes. There is value in conducting mixed methods research, whether the two methods are combined sequentially or independently. Although there appears to be an assumption held by researchers that independent analyses of such data generate more reliable findings, this assumption requires more in-depth examination. Given the greater number of studies which combine mixed methods sequentially, this indicates that the sequential approach has certain benefits to researchers. Sequential mixed methods research allows researchers to collect qualitative data either in anticipation of or following a quantitative study. Such a process permits researchers to gain insight into the organizational and histori-

employing research methods which were qualitative (and often grounded in interpretivist assumptions), some researchers may believe that their results are more convincing to readers if these results are framed as resulting from independent analyses. 
cal context within which the quantitative variables are captured, whether the qualitative data is collected prior to the quantitative data (common in IS studies), or subsequently (Trend 1979; Sutton and Rafaeli 1986). Sequential mixed methods research has the advantage that the researchers can modify their procedures, assumptions, propositions and even their research sites, based upon the first set of results. The disadvantage of independent mixed methods research is that it does not permit such refinements to the propositions and data collection procedures since, in principle, the results from one set of data are not available for the other method to exploit. Perhaps the greatest risk of independent mixed methods research is "not so much that the methods will produce contradictory conclusions as that they will simply diverge leading to noncomparable rather than incompatible ends" (Kidder and Fine 1987, p. 64). Given these potential risks of independent analyses, the offsetting advantages are the fact that the qualitative and quantitative analyses are not constrained by each other and the presumed greater plausibility of the results. The grounds for this latter assumption, however, are called into question by this paper and require further analysis to identify whether they are supported.

Advantages of Both Types of Mixed Methods Research. In articulating the conceptual framework in Table 3 and focusing on differences among mixed methods studies, this paper has necessarily minimized many common features of all mixed methods studies. Mixed methods studies do share certain characteristics. One advantage of mixed methods studies is the opportunity to gather mixed-level data, which can be especially beneficial for linking the individual to the organizational level of analysis. Particularly in studying the effect of new technologies on organizations, such a mixed-level approach can provide benefits. According to Markus and Robey (1988, p. 594):

Technologies such as office automation are neither strictly micro nor macro in character....We believe that mixing levels of analysis may be useful in research and theory on IT and organizational change.....Mixedlevel research should abound in an interdisciplinary field where mixedlevel phenomena are the inevitable subject of study.

There is a clear advantage for researchers studying the impact of IT on organizations to evaluate a technology's influence on micro-level processes before analyzing its ultimate influence on macro processes, as Barley's research demonstrated (1986, 1990). When researchers choose only a single method and single level of analysis to understand IT impacts, problems may result; for example, using firm-level surveys to evaluate IT's impacts at the organizational level, while ignoring changes in microlevel processes that underlie these macro-level changes (Markus and Robey 1988; Leavitt and Whisler 1958). ${ }^{15}$

${ }^{15}$ The benefits of mixed-level theory are not always present in mixed method studies. Employing mixed methods is neither necessary nor sufficient to ensure mixed-level studies. For example, mixed methods may be used so that quantitative and qualitative data may be collected at a single level (e.g., at the company level only). Conversely, if mixed-level theory is the objective, it may be achieved through other means than mixed-method research, for 
A second advantage of mixed methods research is that it has the possibility of reaching both positivist and interpretivist researchers. To positivist researchers, it offers a way of triangulating on multiple perspectives - a technique with a long tradition in the positivist literature (Campbell and Fiske 1959). To qualitative and interpretivist researchers, it offers the opportunity to collect quantitative data to corroborate their field studies. Given these potential benefits of mixed methods research, we return to the earlier observation that mixed quantitative and qualitative research continues to be scarce. Only $1.9 \%$ of published IS studies across a set of leading journals were found to meet the definition of mixed quantitative and qualitative research. Some researchers believe that the research question should dictate the appropriate methods to use and, by extension, that the paucity of mixed methods studies proves that few research questions will benefit from mixed methods. This justification for the scarcity of mixed methods studies is too simplistic. Rather than assuming that the research problem determines the methodology to be followed, an alternative model, such as the "garbage can model" of the research process reverses the direction of causality, claiming that personal preferences, such as "methodological considerations often determine which theoretical problems are addressed" (Martin 1982, p. 30). This "garbage can model" suggests that the researcher's choice of a particular methodology, as well as other "personal concerns of the researcher" (Grady and Wallston 1988; Maxwell 1996), will shape the topics that researchers choose to study, and not vice-versa. This argument suggests that there are obstacles posed by mixed methods research that cause researchers to avoid questions that might benefit from their use, and not a scarcity of suitable research questions that would profit from mixed methods research.

Challenges of Using Mixed Methods. Beyond the obvious challenges, such as the time and expense of collecting and analyzing two sets of data, one important obstacle is researcher training, since the disciplinary preparation of researchers is likely to favor one research paradigm and its associated methods over another (Cook and Reichardt 1979). Even if researchers have learned how to collect and analyze data through both methods, performing the triangulation analysis can be difficult. The real challenge often begins when both analyses are completed and found to contradict each other, and many studies that analyze both types of data often fail to explain how the triangulation analysis was actually conducted (Jick 1979).

Limitations of this study. There are certainly limitations to this work. The framework developed here is preliminary, both in terms of the dimensions of the framework (Table 3) and also the classification of papers into its cells. The review of the IS literature included only four U.S.-based publications. It is possible that different conclusions would be drawn if the literature review included European IS publications, or even another sample of U.S. publications. Further research based on a

example, through research employing a single method to generate data at multiple levels (e.g., analyzing archival data at the individual, the workgroup, or the company level). 
broader set of journals should be conducted to evaluate both the evidence for the scarcity of mixed methods research and the classification of these articles into a theoretical framework.

Further elaboration is also possible on the argument that researchers, when seeking to persuade readers of the significance of their findings, will attempt to convince them of the independence of their analyses. The argument raised here that researchers engage in impression management is novel, but it is supported only with evidence from the authors' perspective and should be supplemented with evidence from the perspective of readers and journal editors. For example, it may be possible to identify biases in readers' perception and judgment that predispose them to be more strongly convinced by mixed methods studies only if the results were generated by independent analyses. Perhaps cognitive studies of how readers evaluate the plausibility of research conclusions can explain why they are less trusting of studies when collection and analysis of one set of data sequentially preceded the other. A deeper understanding of this phenomenon from a cognitive psychology perspective may explain why researchers frame their studies as having followed a certain process.

Although the IFIP 8.2 community has long been one forum for criticizing the preponderance of quantitative, positivist methods, it is also likely to be the strongest channel for broadening the scope of research approaches in IS journals. Like our predecessors who have called for methodological pluralism, my focus on the contributions of mixed methods studies is not intended to replace any other approach, but instead to highlight its unique challenges and benefits. Without expecting to "win over" researchers from the dominant quantitative, positivist tradition or those steeped in purely qualitative research traditions, the belief here is that there are potential benefits to IS researchers in understanding the value of mixed methods in advancing theory development. The objective is that a better awareness of mixed methods research, as an alternative approach, can inform and influence both mainstream quantitative researchers and the increasingly visible qualitative research community (Walsham 1995) in the same way that any minority view normally influences the outlook of the dominant majority. Social psychology research on the effects of minority perspectives on the majority group's information-seeking and decisionmaking behaviors were summarized by Nemeth (1986), "Minority viewpoints are important, not because they tend to prevail but because they stimulate divergent attention and thought. As a result...they contribute to the detection of novel solutions and decisions that, on balance, are qualitatively better."

\section{ACKNOWLEDGMENTS}

I wish to thank Allen Lee, Wanda Orlikowski, Jon Turner, and three anonymous reviewers for many helpful suggestions on previous drafts of the paper. I also wish 
to thank Sivakumar Viswanathan of New York University for his assistance in conducting the literature review.

\section{REFERENCES}

Barley, S. R. (1986). "Technology as an Occasional for Structuring: Evidence from Observations of CT Scanners and the Social Order of Radiology Departments." Administrative Science Quarterly, Volume 31, pp. 78-108.

Barley, S. R. (1990). "The Alignment of Technology and Structure through Roles and Networks." Administrative Sciences Quarterly, Volume 36, pp. 61-103.

Benbasat, I. (1984). "An Analysis of Research Methodologies." In W. McFarlan (Editor), Harvard Colloquium on Information Systems Research. Cambridge, Massachusetts: Harvard University Press, pp. 47-88.

Benbasat, I.; Goldstein, D. K.; and Mead, M. (1987). "The Case Research Strategy in Studies of Information Systems." MIS Quarterly, Volume 11, Number 3, pp. 369-386.

Blanton, J. E.; Watson, H. J.; and Moody, J. (1992). "Toward a Better Understanding of Information Technology Organization: A Comparative Case Study." MIS Quarterly, Volume 16, Number 4, pp. 531-555.

Brown, C. V., and Magill, S. L. (1994). "Alignment of the IS Functions with the Enterprise: Toward a Model of Antecedents." MIS Quarterly, Volume 18, Number 4, pp. 371-397.

Campbell, D. T., and Fiske, D. W. (1959). "Convergent and Discriminant Validation by the Multi-trait -Multi-method Matrix." Psychological Bulletin, Volume 56, pp. 8-105.

Cook, T. D., and Reichardt, D. S. (1970). Quantitative and Qualitative Methods in Evaluation Research. Newbury Park, California: Sage Press.

Daft, R. L., and Lengel, R. H. (1986). "A Proposed Integration among Organizational Information Requirements, Media Richness, and Structural Design." Management Science, Volume 32, Number 5, pp. 191-233.

Daft, R. L.; Lengel, R. H.; and Trevino, L. K. (1987). "Message Equivocality, Media Selection and Manager Performance: Implications for Information Systems." MIS Quarterly, Volume 11, Number 3, pp. 355-366.

Davis, M. S. (1971). "That's Interesting! Towards a Phenomenology of Sociology and a Sociology of Phenomenology." Philosophy of Social Science, Volume 1, pp. 309-344.

Deans, P. C.; Karwan, K. R.; Goslar, M. D.; Ricks, D. A.; and Toyne, B. (1991). "Identification of Key International Information Systems Issues in U.S.-Based Multinational Corporations." Journal of Management Information Systems, Volume 7, Number 4, pp. 27-50.

Denzin, N. K. (1978). The Research Act, Second Edition. New York: McGraw-Hill. 
DeGross, J. I.; Bostrom, R. P.; and Robey, D. (Editors) (1993). Proceedings of the Fourteenth International Conference on Information Systems. Orlando, Florida.

Earl, M. (1993). "Experiences in Strategic Information Systems Planning." MIS Quarterly, Volume 17, Number 1, pp. 1-24.

Eisenhardt, K. M. (1989). "Building Theories from Case Study Research.” Academy of Management Review, Volume 14, Number 4, pp. 532-550.

Finlay, P. N., and Mitchell, A. (1994). "Perceptions of the Benefits From the Introduction of CASE: An Empirical Study." MIS Quarterly, Volume 18, Number 4, pp. 353-369.

Fitzgerald, G.; Hirschheim, R.; Mumford, E.; and Wood-Harper, T. (1985). "Information Systems Research Methodology: An Introduction to the Debate." In E. Mumford, R. Hirschheim, G. Fitzgerald and T. Wood-Harper (Editors), Research Methods in Information Systems. Amsterdam: North-Holland, pp. 3-12.

Fulk, J.; Schmitz, J.; and Steinfield, C. (1990). "A Social Influence Model of Technology Use." in J. Fulk and C. Steinfield (Editors), Organizations and Communication Technology. Newbury Park, California: Sage Press, pp. 117-140.

Golden-Biddle, K., and Locke, K. (1993). “Appealing Work: An Investigation of How Ethnographic Texts Convince." Organization Science, Volume 4, Number 4, pp. 595-616.

Grady, K. A., and Wallston, B. S. (1988). Research in Health Care Settings. Newbury Park, California: Sage Press.

Grant, R. A., and Higgins, C. A. (1991). "The Impact of Computerized Performance Monitoring on Service Work: Testing a Causal Model." Information Systems Research, Volume 2, Number 2, pp. 116-142.

Griffith, T. L., and Northcraft, G. B. (1996). "Cognitive Elements in the Implementation of New Technology: Can Less Information Provide More Benefits?" MIS Quarterly, Volume 20, Number 1, pp. 99-110.

Hackman, J. R., and Oldham, G. (1980). Work Design. Reading, Massachusetts: Addison-Wesley.

Ives, B., and Olson, M. H. (1984). "User Involvement and MIS Success: A Review of Research.” Management Science, Volume 30, Number 5, pp. 586-603.

Jarvenpaa, S., and Ives, B. (1991). "Executive Involvement and Participation in the Management of Information Technology.” MIS Quarterly, Volume 15, Number 2, pp. 205-228.

Jick, T. (1979). “Triangulating on Mixing Qualitative and Quantitative Methods: Triangulation in Action." Administrative Science Quarterly, Volume 24, pp. 602611.

Jobber, D.; Saunders, J.; Gilding, B.; Hooley, G.; and Hatton-Smoker, J. (1989). "Assessing the Value of a Quality Assurance Certificate for Software: An Exploratory Investigation." MIS Quarterly, Volume 13, Number 1, pp. 19-31.

Kaplan, B., and Duchon, D. (1988). "Combining Qualitative and Quantitative Methods in Information Systems Research: A Case Study." MIS Quarterly, Volume 12, Number 4, pp. 571-586. 
Kidder, L., and Fine, M. (1987). "Qualitative and Quantitative Methods: When Stories Converge." In M. M. Mark and R. L. Shotland (Editors), Multiple Methods in Program Evaluation. San Francisco: Jossey-Bass, pp. 57-76.

Konsynski, B. R. (1993). "A Perspective on the 'Case Study Approach' in Evaluating the Business Value of Information Technology." In R. D. Banker, R. J. Kauffman, and M. Mahmood (Editors), Strategic Information Technology Management. Harrisburg, Pennsylvania: Idea Group Publishing, pp. 15-24.

Kraut, R.; Dumais, S.; and Koch, S. (1989). "Computerization, Productivity and the Quality of Work Life." Communications of the ACM, Volume 32, Number 2, pp. 220-238.

Lacity, M. C., and Janson, M. (1994). "Understanding Qualitative Data: A Framework of Text Analysis Methods." Journal of Management Information Systems, Volume 11, Number 2, pp. 137-155.

Lee, A. S. (1989). "A Scientific Methodology for MIS Case Studies." MIS Quarterly, Volume 13, Number 1, pp. 33-50.

Lee, A. S. (1991). "Integrating Positivist and Interpretivist Research Approaches: Approaches to Organizational Research." Organization Science, Volume 2, Number 4, pp. 342-365.

Leidner, D. E., and Jarvenpaa, S. L. (1993). "The Information Age Confronts Education: Case Studies on Electronic Classrooms." Information Systems Research, Volume 4, Number 1, pp. 24-54.

Leonard-Barton, D. (1990). "A Dual Methodology for Case Studies: Synergistic Use of a Longitudinal Single Site with Replicated Multiple Sites." Organization Science, Volume 1, Number 3, pp. 248-266.

Leavitt, H. J., and Whisler, T. L. (1958). "Management in the 1980s." Harvard Business Review, November-December, pp. 41-48.

Liker, J. K.; Roitman, D. B.; and Roskies, E. (1987). "Changing Everything All at Once: Work Life and Technological Change." Sloan Management Review, pp. 2947.

Markus, M. L. (1994). "Electronic Mail as the Medium of Managerial Choice." Organization Science, Volume 5, Number 4, pp. 502-527.

Markus, M. L., and Robey, D. (1988). "Information Technology and Organizational Change: Causal Structure in Theory and Research." Management Science, Volume 34, pp. 583-598.

Martin, J. (1982). "A Garbage Can Model of the Research Process." In J. McGrath, J. Martin and R. Kulka (Editors), Judgment Calls in Research. Beverly Hills: Sage Press, pp. 17-40.

McGrath, J. (1982). "Dilemmatics: The Study of Research Choices and Dilemmas." In J. McGrath, J. Martin, and R. Kulka (Editors), Judgment Calls in Research. Beverly Hills: Sage Press, pp. 69-102.

Maxwell, J. A. (1993). "Combining Qualitative and Quantitative Methods." Unpublished manuscript, Harvard University Graduate School of Education. 
Maxwell, J. A. (1996). Qualitative Research Design: An Iterative Approach. Thousand Oaks, California: Sage Press.

Mohr, L. B. (1982). Explaining Organizational Behavior. San Francisco: JosseyBass.

Moynihan, T. (1990). "What Chief Executives and Senior Managers Want From Their IT Departments." MIS Quarterly, Volume 14, Number 1, pp. 15-26.

Nemeth, C. J. (1986). "Differential Contributions of Majority and Minority Influence." Psychological Review, Volume 93, Number 1, pp. 23-32.

Nissen, H-E. (1985). "Acquiring Knowledge of Information Systems Research in a Methodological Quagmire.” In E. Mumford, R. Hirschheim, G. Fitzgerald and T. Wood-Harper (Editors), Research Methods in Information Systems. Amsterdam: North-Holland, pp. 39-51.

Orlikowski, W. J. (1989). "Division among the Ranks: The Social Implications of CASE Tools for System Developers.” In J. I. DeGross, J. C. Henderson, and B. R. Konsynski (Editors), Proceedings of the Tenth International Conference on Information Systems. Boston, Massachusetts, pp. 199-210.

Orlikowski, W. J. (1993). “CASE Tools as Organizational Change: Investigating Incremental and Radical Changes in Systems Development." MIS Quarterly, Volume 17, Number 3, pp. 309-340.

Orlikowski, W. J. (1996). "Improvising Organization and Transformation Over Time: A Situated Change Perspective." Information Systems Research, Volume 17, Number 1, pp. 63-92.

Orlikowski, W. J., and Baroudi, J. J. (1991). "Studying Information Technology in Organizations: Research Approaches and Assumptions." Information Systems Research, Volume 2, Number 1, pp. 1-28.

Poole, M. S., and Van de Ven, A. H. (1989). "Using Paradox to Build Management and Organization Theories." Academy of Management Review, Volume 14, pp. 562-578.

Reich, B. H., and Benbasat, I. (1996). "Measuring the Linkage Between Business and Information Technology Objectives." MIS Quarterly, Volume 20, Number 1, pp. 55-77.

Robey, D. (1995). "Theories that Explain Contradiction: Accounting for the Contradictory Organizational Consequences of Information Technology." In J. I. DeGross, G. Ariav, C. M. Beath, R. W. Hoyer, and C. Kemerer (Editors), Proceedings of the Sixteenth International Conference on Information Systems. Amsterdam, The Netherlands, pp. 55-63.

Rogers, E. M. (1983). Diffusion of Innovations, Second Edition. New York: Free Press.

Sabherwal, R., and Robey, D. (1995). "Reconciling Variance and Process Strategies for Studying Information System Development." Information Systems Research, Volume 6, Number 4, pp. 303-327. 
Smith, H. J.; Milberg, S. J.; and Burke, S. J. (1996). "Information Privacy: Measuring Individuals' Concerns about Organizational Practices." MIS Quarterly, Volume 20, Number 2, pp. 167-196.

Soh, C., and Markus, M. L. (1995). "How IT Creates Business Value: A Process Theory Synthesis." In J. I. Degross, G. Ariav, C. Beath, R. Hoyer and C. Kemerer (Editors), Proceedings of the Sixteenth International Conference on Information Systems. Amsterdam, The Netherlands, pp. 29-41.

Sutton, R. I., and Rafaeli, A. (1986). "Untangling the Relationship between Displayed Emotions and Organizational Sales: The Case of Convenience Stores." Academy of Management Journal, Volume 31, Number 3, pp. 461-487.

Trend, M. G. (1979). "On the Reconciliation of Qualitative and Quantitative Analyses: A Case Study." In T. D. Cook and D. S. Reichardt (Editors), Quantitative and Qualitative Methods in Evaluation Research. Thousand Oaks, California: Sage Press, pp. 68-86.

Trauth, E. M.; Farwell, D. W.; and Lee, D. (1993). "The IS Expectation Gap: Industry Expectations Versus Academic Preparation." MIS Quarterly, Volume 17, Number 3, pp. 293-303.

Tyran, C. K.; Dennis, A. R.; Vogel, D. R.; and Nunamaker Jr., J. F. (1992). "The Application of Electronic Meeting Technology to Support Strategic Management." MIS Quarterly, Volume 16, Number 3, pp. 313-334.

Walsham, G. (1995). "The Emergence of Interpretivism in IS Research." Information Systems Research, Volume 6, Number 4, pp. 376-394.

Watson, R. T. (1990). "Influence on the IS Manager's Perceptions of Key Issues: Information Scanning and the Relationship With the CEO." MIS Quarterly, Volume 14, Number 2, pp. 217-231.

Wynekoop, J. L. (1992). "Strategies for Implementation Research: Combining Research Methods." In J. I. DeGross, J. D. Becker, and J. J. Elam (Editors), Proceedings of the Thirteenth International Conference on Information Systems. Dallas, Texas, pp. 185-193.

Wynekoop, J. L., and Conger, S. A. (1991). "A Review of Computer Aided Software Engineering Research Methods." In H-E. Nissen, H. K. Klein and R. Hirschheim (Editors), Information Systems Research: Contemporary Approaches and Emergent Traditions. Amsterdam: North-Holland, pp. 301-327.

Wynekoop, J. L., and Russo, N. L. (1993). "System Development Methodologies: Unanswered Questions and the Research-Practice Gap." In J. I. DeGross, R. P. Bostrom, and D. Robey (Editors), Proceedings of the Fourteenth International Conference on Information Systems. Orlando, Florida, pp. 181-190.

Yin, R. K. (1994). Case Study Research: Design and Methods, Second Edition. Newbury Park, California: Sage Press.

Zack, M. H., and McKenney, J. L. (1995). "Social Context and Interaction in Ongoing Computer-Supported Management Groups." Organization Science, Volume 6, Number 4, pp. 394-422. 